\title{
Assessment of the importance of spatial scale in long-term land use modeling of the Midwestern United States
}

\author{
Page Kyle ${ }^{*}$, Allison Thomson, Marshall Wise, and Xuesong Zhang \\ Joint Global Change Research Institute, Pacific Northwest National Laboratory, 5825 \\ University Research Ct, Suite 3500, College Park, MD 20740 \\ * Corresponding author. email: pkyle@pnnl.gov, Tel.: +1-301-314-6758
}

\begin{abstract}
This study assesses the value of enhanced spatial resolution in the agriculture and land use component of an integrated assessment (IA) model. IA models typically represent land use decisions at finer resolution than the energy and economic components, to account for spatial heterogeneity of land productivity and use. However, increasing spatial resolution incurs costs, from additional input data processing, run time, and complexity of results. This study uses the Global Change Assessment Model (GCAM) to analyze land use in the Midwestern United States in three levels of spatial aggregation, and three climate change mitigation scenarios. For visualization and simplification of higher resolution model output, we use non-metric multidimensional scaling. We find that the level of spatial aggregation influences the magnitude but not the direction of land use change in response to the modeled drivers, and in the examples analyzed, increasing spatial resolution reduces the extent of land use change.
\end{abstract}

\section{Keywords}

Integrated assessment; multivariate statistics; non-metric multidimensional scaling; agriculture and land use

\section{Introduction}

Global economic models of agriculture and land use represent land decisions at a wide range of spatial scales, reflecting different model focal areas, and including consideration of integration with other economic sectors, data availability, levels of investment in data processing and computing resources, and model time horizons, among other factors. At 
one end of the spectrum, gridded land use models such as MagPIE (Lotze-Campenn et al. 2008) and GLOBIOM (Havlik et al. 2011) represent land use decisions within each $0.5^{\circ} \mathrm{x}$ $0.5^{\circ}$ grid cell, the largest of which are approximately 2500 square kilometers. In contrast, until recently, most integrated models that link land and agriculture with energy and the economy represented land use decisions at the scale of geopolitical macro-regions, the largest of which was often Africa, about 30 million square kilometers (Paltsev et al. 2005; Wise et al. 2009; Masui et al. 2011; Thomson et al. 2011).

Recent datasets characterizing present-day agriculture and land cover have facilitated efforts to enhance the spatial resolution of the current generation of global agro-economic models. Presently available gridded datasets include total pasture and cropland area (HYDE; Klein Goldewijk et al. 2011), irrigated and rainfed harvested area by 26 crop types (MIRCA; Portmann et al. 2010), and production and harvested area by 20 crop types (SPAM; You et al. 2006). Production and harvested area for 175 crop types are available at the level of up to 18 agro-ecological zones within 226 countries (Monfreda et al. 2009). It is likely that in upcoming years, data sets with even higher spatial and land use resolution will continue to be developed. For example, use of recently available satellite imagery has facilitated development of land use data, including the Cropland Data Layer with agricultural crops specified at 56m spatial resolution for the United States (Johnson and Mueller, 2010), and additional MODIS and MERIS imagery based products have recently been made available for global land cover product development (Channan et al., 2014; ESA, 2014). Given that global agro-economic models are being used increasingly for assessments of climate change impacts (e.g., Nelson et al. 2014) and water scarcity (e.g., Hejazi et al. 2014), it is also likely that the spatial resolution in these models will continue to increase.

While enhancing the spatial resolution of global agro-economic models has the obvious benefit of improved land cover specificity, it also presents challenges in analysis and visualization of land use change patterns to discern significant trends. Many studies have presented maps of individual output variables, for instance the portion of each grid cell that is cropland or forest (e.g., Hurtt et al. 2011; Klein Goldewijk et al. 2011). However, global agro-economic models typically include dozens of different land cover types, so responses can not always be meaningfully indicated by individual output variables. Other 
studies have conducted data analysis at a coarser level of spatial resolution than was actually modeled, often by aggregating model results to between 7 and 15 global macroregions (e.g., Lotze-Campenn et al. 2008; Schmitz et al. 2014; von Lampe et al. 2014). A third strategy has been to provide analysis of land use dynamics from global agroeconomic models at finer spatial scales by focusing on individual regions of interest (e.g., Mosnier et al. 2013; Thomson et al. 2014). Model intercomparisons have been conducted to examine different model land change outcomes in response to coordinated policy assumptions (Nelson et al., 2014; Popp, et al., 2014) and literature reviews have surveyed the differences in methodology between global land change economic models, including spatial scale (Heistermann et al., 2006; Wise et al., 2014). Several recent within-model diagnostic studies have addressed the impacts of using different land sharing algorithms (Fujimori et al., 2014), and different spatial clustering and aggregation schemes for reducing the number of land use regions modeled individually (Dietrich et al., 2013). This study starts by addressing what is actually different in global agro-economic model outcomes when a region of interest is simulated with the same input data aggregated to different regional resolutions, addressing a need identified in previous literature reviews of global agro-economic modeling (Heistermann et al 2006). Our study region is a group of 14 Midwestern and Mid-Atlantic states in the United States whose total land area is about 2.2 million square kilometers, shown in Figure 1. This region accounts for approximately 80 percent of U.S. corn and soybean production, mostly in the western half, which has received recent attention in agro-economic and crop modeling research (e.g., Glotter et al. 2014; Thomson et al. 2014; Zhang et al. 2014). However even within the predominantly agricultural portion of the study region, there are significant inter-state differences in what types of crops are grown, and states in the eastern half of the study region are mostly forested. We assess model-derived estimates of land cover by land use type in several scenarios, treating the study region as a one model region, as 14 states, and as 37 subregions defined by the intersection of state and crop management zone boundaries (CMZs). CMZs are distinguished by conditions that are relevant for agriculture; there are 78 nationally, of which 12 are found in the study region (USDANRCS 2014). Land use regions in non-gridded agro-economic models are typically formed through a similar intersection of political and physical boundaries, whether 
hydrologic watersheds (e.g., IMPACT's Food Production Units; Rosegrant et al. 2008), temperature and precipitation gradients (e.g., GTAP's Agro-Ecological Zones; Monfreda et al. 2009), or other criteria.

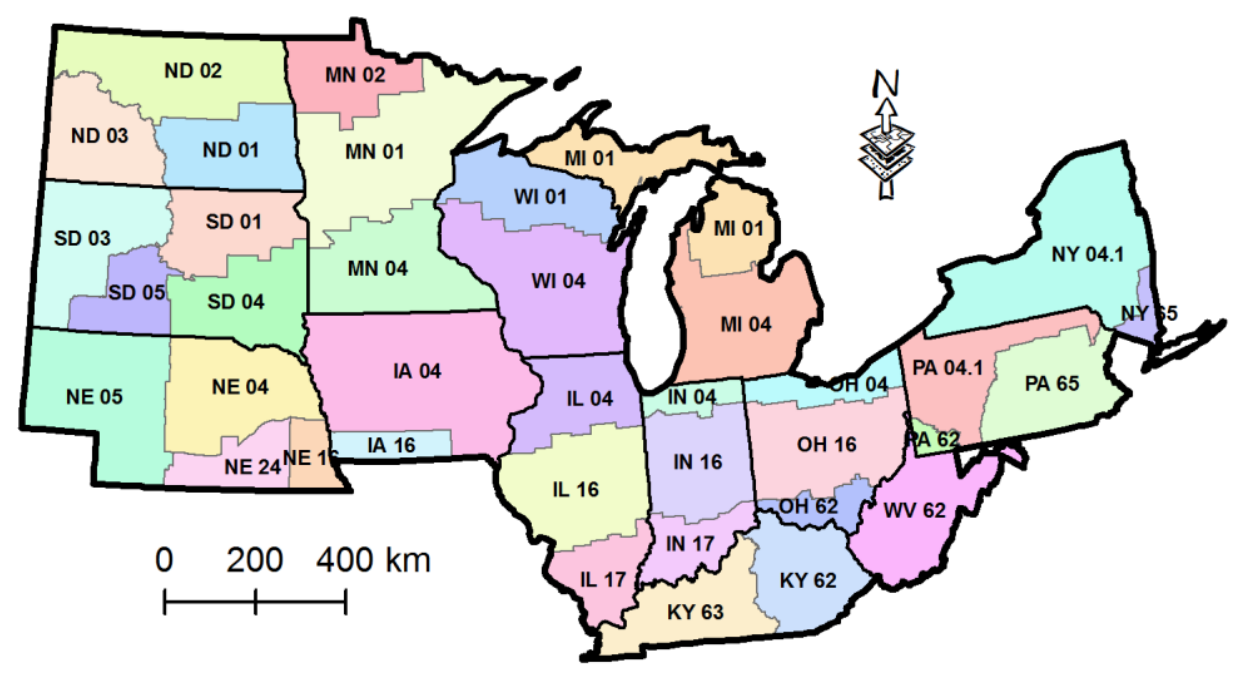

\section{Figure 1. Map of the study region, highlighting both state and crop management zone (CMZ) boundaries.}

The next part of our study addresses land cover differences between the 14- and 37region outcomes at the state level, as these spatial scales — between 136,000 and 51,000 square kilometers on average, respectively - are relevant for the current development of global agro-economic models. Note that many regional land use models operate at much finer spatial scales, and have been used to add detail to global model results (e.g., Britz et al. 2011; Mas et al. 2014; Murray-Rust et al. 2014); nevertheless, this study focuses on the appropriate level of detail for land use regions in a global model whose functional forms and computing constraints would not lend themselves to very fine scale, or agentbased modeling. Our analysis method for conducting these multi-state comparisons of many land cover types may be broadly applicable for agro-economic modeling, given that the current analysis and visualization methods in the published literature are inefficient for the already large and increasing number of model regions, response variables, and scenarios being analyzed. Specifically, we construct a pair-wise distance matrix and conduct non-metric multidimensional scaling, collapsing variability among 
states, years, policy scenarios, and region aggregation levels into a two-dimensional scatterplot in order to facilitate comparison and analysis between all observations. First developed by Kruskal (1964), this method is commonly used in community ecology, where the composition of each plot is indicated by the relative abundance of different species or aggregations thereof (Legendre and Legendre 1998; McCune and Grace 2002). To our knowledge it has not been applied to analysis of agro-economic model output.

\section{Methods}

This study analyzes land use dynamics in a set of scenarios constructed in the Global Change Assessment Model (GCAM, version 3.2, revision 4704), an integrated assessment model of energy supply and demand, agriculture and land use, greenhouse gas emissions and climate. GCAM is a community model with a global user community of over 250 research teams. The code, input data and tutorial information are available for download from http://www.globalchange.umd.edu/models/gcam/gcam-community/ and fully documented at http://wiki.umd.edu/gcam in addition to in a number of journal articles. While GCAM is a global model, which tracks the global supplies and demands of all commodities modeled, the present study focuses entirely on dynamics within an individual study region of interest nested within the global model. Regional definition in GCAM is governed by data inputs; changing spatial resolution therefore requires only changing input data and no changes to the underlying model code. Similar studies could be conducted within any agro-economic model, not just one that includes full global coverage or an embedded energy model.

The agricultural and land use module of GCAM is documented in Wise et al. (2014), Kyle et al. (2011) and Wise and Calvin (2011); in summary, land use regions are typically defined as the intersection of GCAM's 14 geopolitical regions and 18 agroecological zones (AEZs) documented in Monfreda et al. (2009). However, because land use regions are built from global gridded datasets, alternative regional constructions are possible; this study disaggregates a study region using different criteria, described below. Within the study region used here, land may be allocated to up to 40 different land uses, using a nested logit sharing mechanism that is calibrated to base-year (2005) land area shares. Of particular importance for the present study, the land shares in any region and 
future time period are based on the profitability of each possible land use type, as compared with its profitability and land share in the base year. The main drivers for changes in the profitability of any land use type are changes in yields, crop prices, and in scenarios with emissions mitigation policies that include carbon emissions pricing, the average carbon content of the soils and vegetation.

The study region, shown in Figure 1 and documented in Thomson et al. (2014), consists of 14 states that cover about 2.2 million square kilometers of land, and include 12 of the 78 Crop Management Zones (CMZs) defined by the USDA-NRCS (2014). The intersection of states and CMZs yields a maximum of 37 land use regions within the study region. Note that the AEZs of the global model are not used within the study region. To define the different land use regions within the study region, the input data system (Kyle et al., 2011) was run three times with the high resolution agriculture input dataset described in Thomson et al (2014), with our three different spatial aggregations of interest (1 region, 14 regions, and 37 regions). GCAM was then calibrated globally for 2005 using each of the three aggregations and run forward through 2095 for three scenarios of climate policy (Table 1).

This study region is important for agriculture, producing about $80 \%$ of the country's corn and soybeans, and $40 \%$ of the wheat (USDA-NASS 2014). Most of the agricultural production occurs in the central and western states, with the eastern states being mostly forested, not in crop production. Figure 2 highlights the diversity of land use among the 14 states in the study region. 


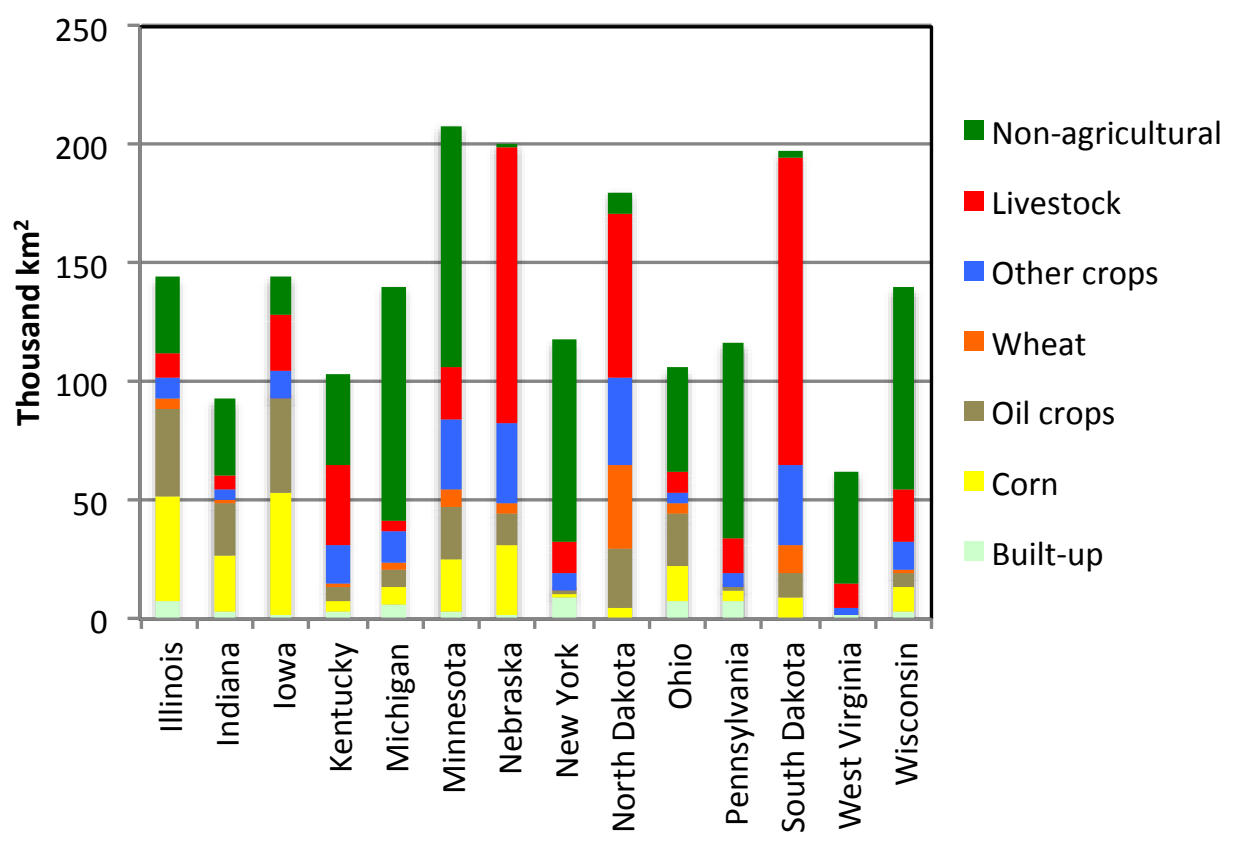

Figure 2. Base-year (2005) land use in the study region by state, in thousand square kilometers. "Non-agricultural" refers to land in non-grazed grassland and forest; "livestock" refers to land in forage crops and pasture; and "oil crops" includes soybeans and a variety of oil seeds.

This study assesses land use in these states from the calibration year, 2005, through the final model year, 2095, using the three levels of regional aggregation described above, and three levels of future greenhouse gas emissions policy that are directly relevant for land use decisions. (Table 1). These policies include a reference scenario with no emissions mitigation, and two mitigation levels simulated using a global policy that values all carbon emissions from energy and land systems equally, as documented in Wise et al (2009) and Thomson et al. (2011). GCAM solves for economic activity and resultant greenhouse gas and aerosol emissions such that total radiative forcing in the atmosphere stabilizes at $4.5 \mathrm{~W} / \mathrm{m}^{2}$ or $3.7 \mathrm{~W} / \mathrm{m}^{2}$ by 2095 , corresponding to global atmospheric $\mathrm{CO}_{2}$ concentrations of $529 \mathrm{ppmv}$ and $460 \mathrm{pmmv}$, respectively. These scenarios correspond to the mid-range Representative Concentration Pathway assessed by the recent IPCC report (RCP4.5) (IPCC, 2013)) and a more stringent mitigation target widely used in the integrated assessment literature (van Vuuren et al., 2006; Waldhoff et 
al., 2014; Kriegler et al., 2014). In contrast, scenarios with no emissions mitigation reach about $7.2 \mathrm{~W} / \mathrm{m}^{2}$ in 2095 .

Table 1. Scenarios considered in this study.

\begin{tabular}{lllc} 
Scenario & Emissions mitigation & Aggregation level & $\mathbf{C O}_{2}(\mathbf{p p m v})$ in 2095 \\
\hline Ref: 1 & No mitigation & 1 single region & 814 \\
4.5: 1 & $4.5 \mathrm{~W} / \mathrm{m}^{2}$ & 1 single region & 529 \\
3.7: 1 & $3.7 \mathrm{~W} / \mathrm{m}^{2}$ & 1 single region & 460 \\
Ref: 14 & No mitigation & 14 states & 812 \\
4.5: 14 & $4.5 \mathrm{~W} / \mathrm{m}^{2}$ & 14 states & 529 \\
3.7: 14 & $3.7 \mathrm{~W} / \mathrm{m}^{2}$ & 14 states & 460 \\
Ref: 37 & No mitigation & 37 states and CMZs & 812 \\
4.5: 37 & $4.5 \mathrm{~W} / \mathrm{m}^{2}$ & 37 states and CMZs & 529 \\
$3.7: 37$ & $3.7 \mathrm{~W} / \mathrm{m}^{2}$ & 37 states and CMZs & 460 \\
\hline
\end{tabular}

We consider the land change outcomes at the level of the whole study region, and also compare the outcomes at the level of 14 states, for the scenarios with 14 or 37 land use regions. In support of the latter comparison, this study uses multivariate statistical methods: first, we compute a Euclidean distance matrix from the shares of land allocated to each of seven aggregated land use classes, in each scenario in 2050 and 2095, as well as the base year. To facilitate comparison of these runs with different spatial units, the model output from the 37-region runs is aggregated to the 14-state level, and the land cover quantities from 40 modeled land use types are aggregated to seven land cover classes, as indicated in Table A2 of the Supplementary Materials. These classes are the same as shown in Figure 2, excluding built-up land, which is exogenous in GCAM, and including dedicated bioenergy crops - switchgrass and poplar-which are assumed to be available as a land use option starting in 2020. We then conduct Kruskal's Non-metric Multidimensional Scaling (NMDS; Kruskal 1964) on the Euclidean distance matrix in order to collapse the variability in land allocation among the 7 land use types into a twodimensional coordinate plane. The specific methods we have adopted for the multivariate analysis are documented and compared with several alternatives in the Supplementary Materials, which also include some diagnostic tests. 


\section{Results and Discussion}

While the analysis in this study is focused on the study region, the global context may also be of interest; future demographic, economic, and agricultural indicators are available in the Supplementary Materials.

\section{Land Use in the Whole Study Region}

At the scale of the entire study region, different levels of spatial aggregation produce somewhat different results for land allocation in the 2050 and 2095 time periods, shown in Figure 3. Still, all three levels of aggregation show similar patterns of land change from the base year (2005) to each future time period (2050 and 2095) and each emissions mitigation level (Ref, $4.5 \mathrm{~W} / \mathrm{m} 2$, or $3.7 \mathrm{~W} / \mathrm{m} 2$ ).

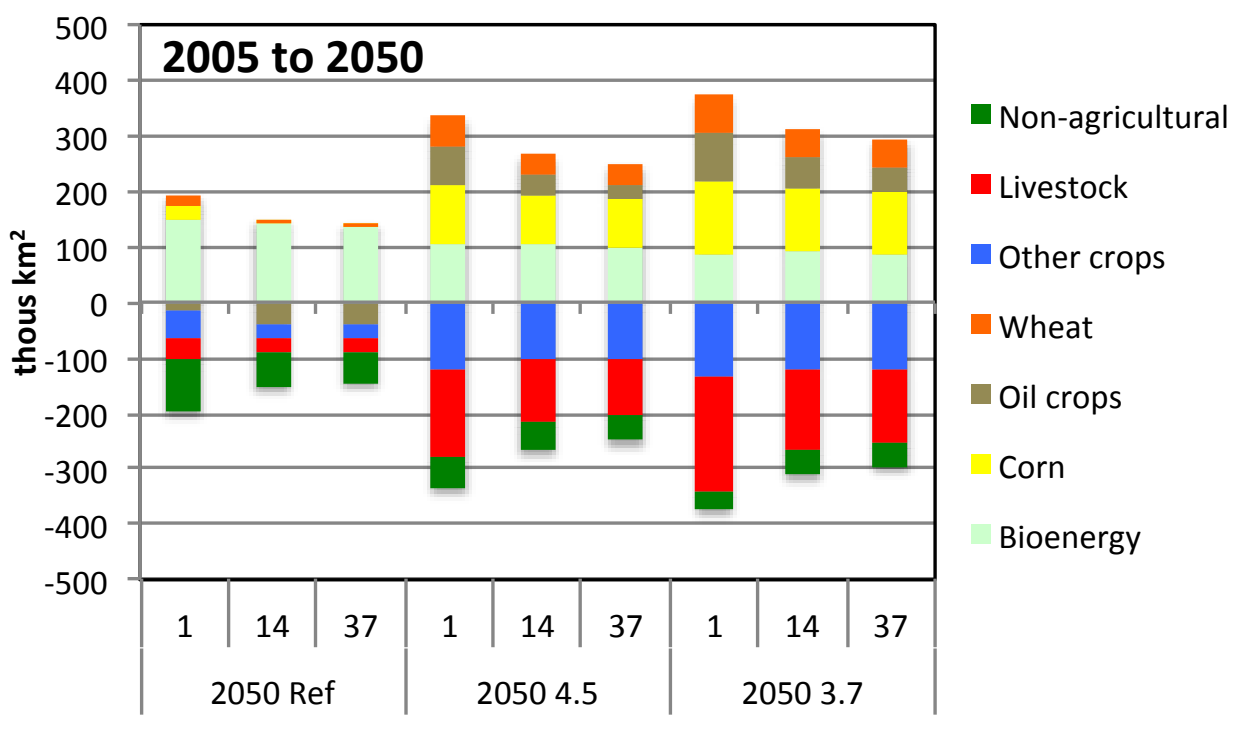




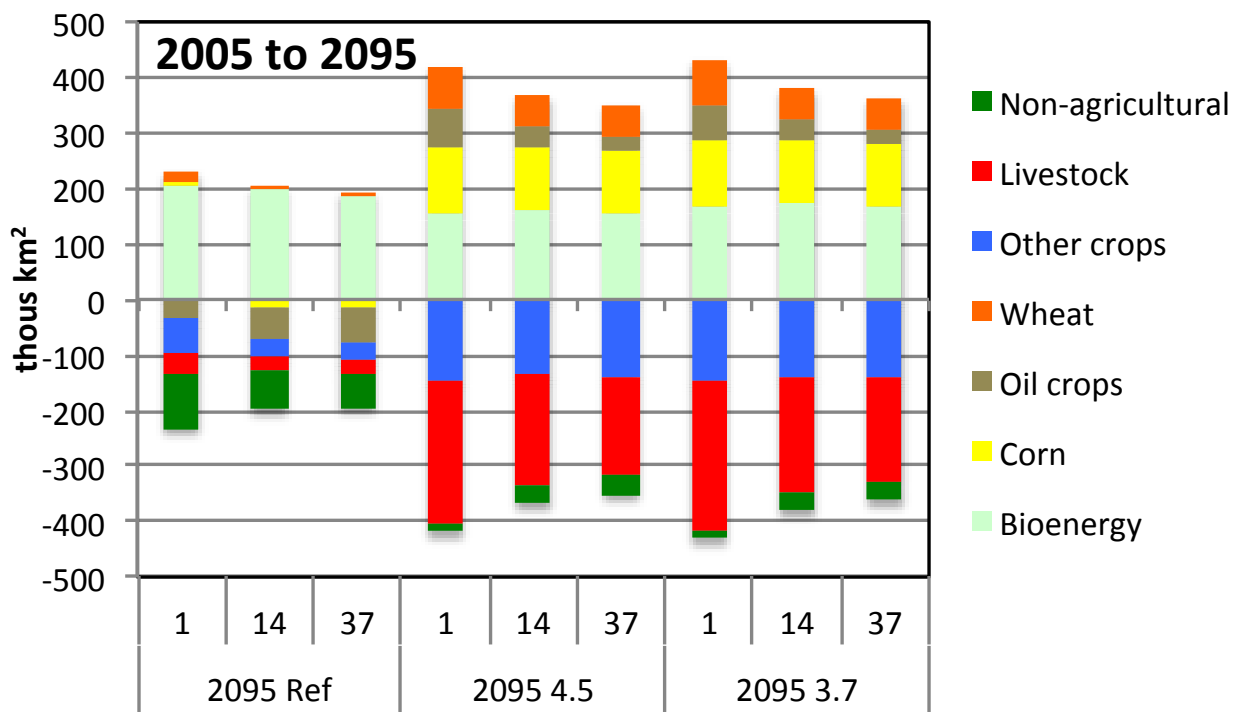

Figure 3. Change in land use from the base year (2005) to 2050 (top panel) and to 2095 (bottom panel) in three levels of sub-regional aggregation $(1,14$, and 37$)$, and three levels of emissions mitigation: Ref (none), $4.5 \mathrm{~W} / \mathrm{m} 2$, and $3.7 \mathrm{~W} / \mathrm{m} 2$ stabilization by 2100.

With no emissions mitigation policy, the land use transitions from 2005 to 2050 and 2095 are characterized by an expansion of land used for dedicated bioenergy crops, from 0 in the base year to as much as $200,000 \mathrm{~km}^{2}$ in 2095 , equal to $11 \%$ of total study region land cover. The demand for bioenergy in these no-policy scenarios is driven primarily by economics in the energy transformation and demand sectors at a global level: as global energy service demands increase with incomes, and fossil fuel prices increase as resources are depleted, the demand for all renewable forms of energy grows substantially. This expansion of land used for bioenergy crop production in the study region is balanced mostly by reductions in non-agricultural land, but also land used for livestock production (pastures and fodder crops), and crops other than corn and wheat.

In emissions mitigation scenarios, the results are generally consistent with Thomson et al. (2014), in that the Midwestern US tends to focus agriculture towards corn, oil crops, and wheat, the commodities where it has an especially large comparative advantage as compared with other regions of the USA and the world. Compared with the reference scenarios, these policy scenarios see a decrease in bioenergy, livestock, and other crops. 
While the emissions mitigation policy drives an increase in bioenergy demand at a global level, the land carbon pricing tends to increase the opportunity cost of agricultural land (due to relatively low carbon densities), enhancing the degree of land use specialization according to comparative advantage. In the study region as a whole, the scenarios indicate that the comparative advantages lie in corn, wheat, soybeans, and nonagricultural land (for carbon storage), but not bioenergy. These results are borne out in all spatial aggregation schemes analyzed here.

As documented elsewhere in scenarios using GCAM (Wise et al. 2009; Thomson et al. 2011), the emissions mitigation policy causes an increase in non-agricultural lands (relative to the reference scenario, not the base year), due to the relatively high carbon contents of non-agricultural lands, particularly forests, and an emissions mitigation policy that values carbon stored in vegetation and soils. Of particular interest, the increase in non-agricultural lands from the reference to the $4.5 \mathrm{~W} / \mathrm{m}^{2}$ emissions mitigation level and to the $3.7 \mathrm{~W} / \mathrm{m}^{2}$ level is most pronounced with the greatest amount of sub-regional aggregation; the study area sees the greatest increase when simulated as a single region.

\section{Corn}

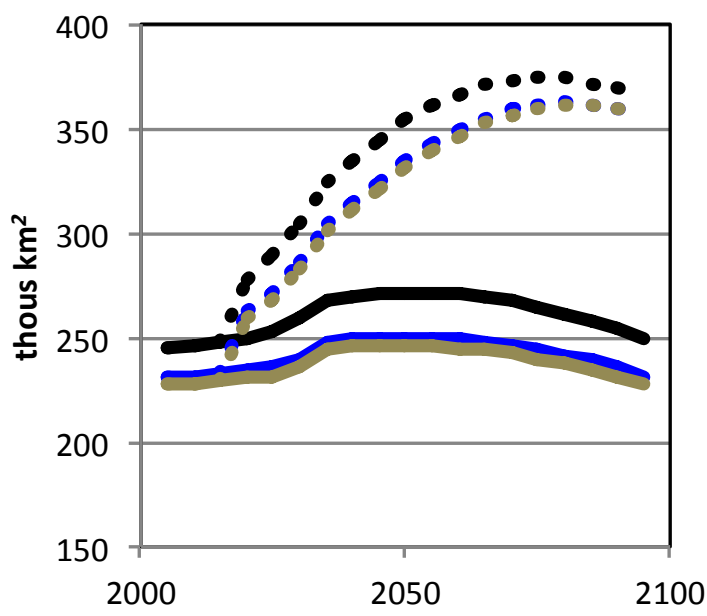

Oil crops

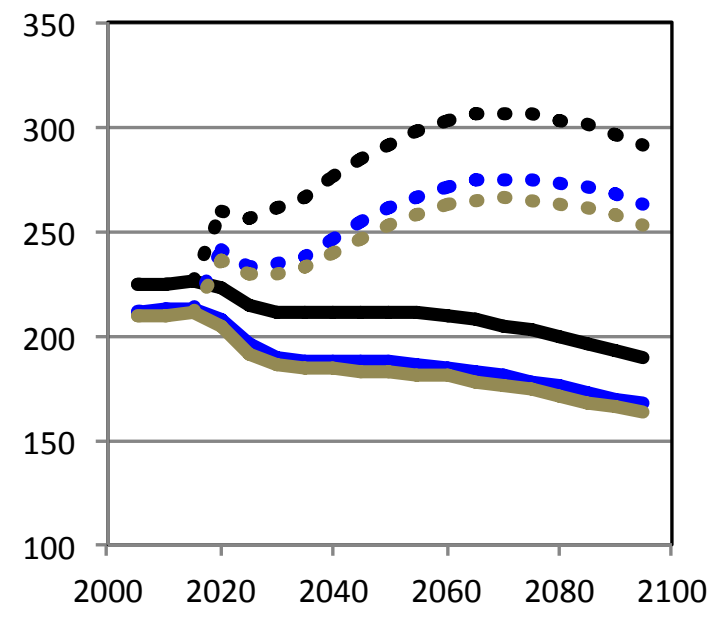



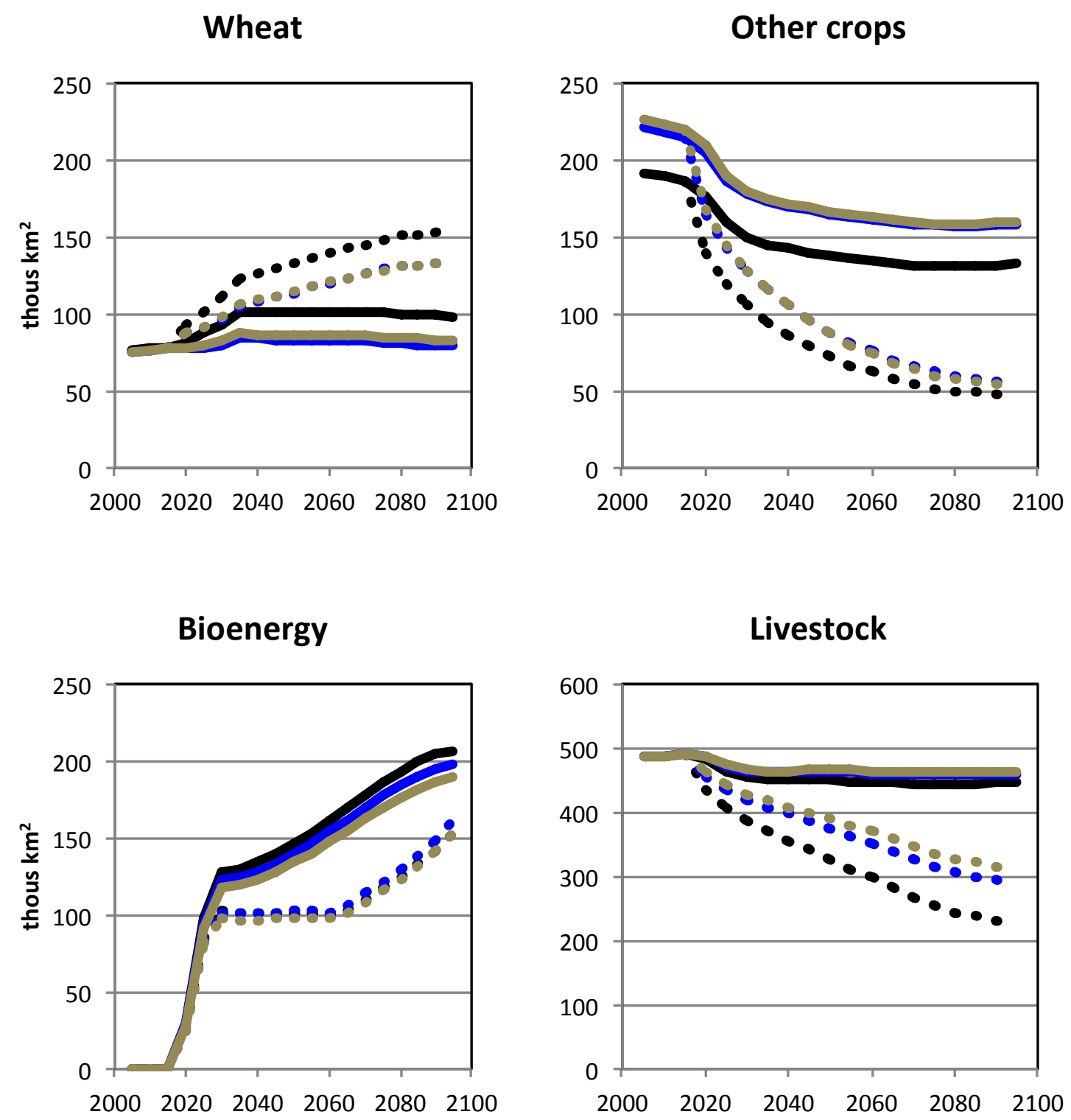


\section{Non-agricultural land}

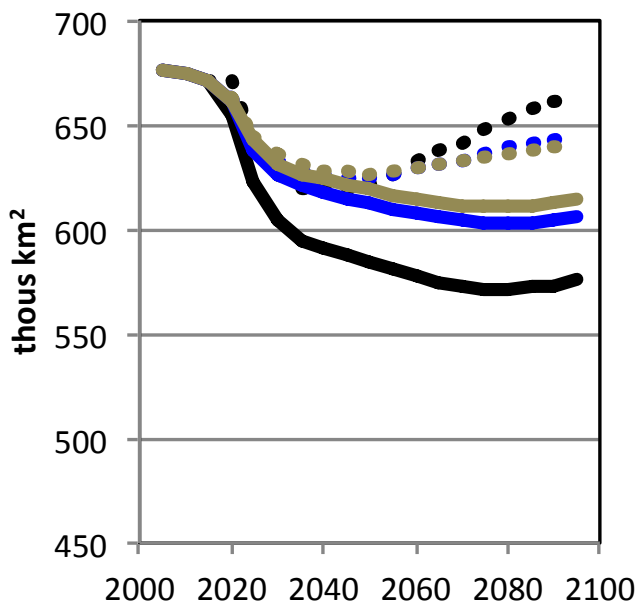

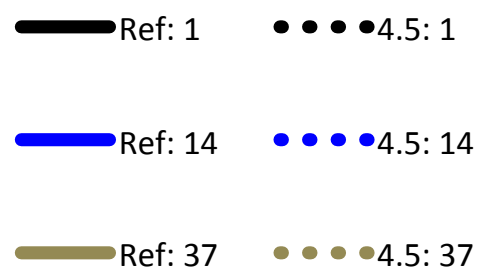

Figure 4. Land cover by seven land use types, with three levels of aggregation (1 region, 14 states, and 37 states and CMZs) and two emissions scenarios (reference and $4.5 \mathrm{~W} / \mathrm{m}^{2}$ policy).

Figure 4 shows these land use trajectories over time for the individual land types and selected scenarios. Note that for corn and oil crops, the different aggregation schemes result in somewhat different land allocations in the base years. This is due to inconsistencies between the gridded dataset used to set total cropland within any region, and the census-based estimates of harvested area by crop that are used to assign total cropland to individual crop types. Nevertheless, focusing on the trends, in nearly all cases, the single-region aggregation scheme shows the greatest capacity for land use change in response to the modeled drivers. This is explored further in Table 2, which shows the difference from the reference to the $4.5 \mathrm{~W} / \mathrm{m}^{2}$ scenarios, for the 1-, 14-, and 37-region aggregation schemes.

Table 2. Policy-related change in land cover (in thousand $\mathbf{~ k m}^{2}$ ) in 2095 from reference to $4.5 \mathrm{~W} / \mathrm{m}^{2}$ scenarios, for 1-, 14-, and 37-region runs, and percentage-wise comparisons in these changes when going from finer to coarser resolution (e.g., from 14 land use regions to 1 land use region).

\begin{tabular}{|l|c|c|c|c|c|}
\hline \multirow{3}{*}{ Land Use } & \multicolumn{3}{|c|}{ Policy effect } & \multicolumn{2}{c|}{ Comparisons } \\
\cline { 2 - 6 } & 1 & 14 & 37 & 1 vs 14 & 14 vs 37 \\
\hline
\end{tabular}




\begin{tabular}{|l|ccc|cc|} 
Bioenergy & -53 & -36 & -36 & $45 \%$ & $1 \%$ \\
Corn & 116 & 125 & 130 & $-8 \%$ & $-4 \%$ \\
Oil crops & 103 & 96 & 90 & $7 \%$ & $6 \%$ \\
Wheat & 56 & 55 & 51 & $2 \%$ & $8 \%$ \\
Other crops & -86 & -104 & -108 & $-17 \%$ & $-3 \%$ \\
Livestock & -222 & -173 & -153 & $28 \%$ & $13 \%$ \\
Non-agricultural & 86 & 37 & 26 & $131 \%$ & $44 \%$ \\
\hline
\end{tabular}

As shown in Table 2, the direction of the effect of the policy in the pilot region as a whole is the same for each land use type with 1, 14, and 37 land use regions, but among land use types, we observe the greatest difference in responsiveness for non-agricultural land. That is, in response to the same economic drivers, switching from a 14-region approach to a single-region approach leads to greater change in non-agricultural land than any other land use types. This difference is also evident but not as pronounced in going from 37 to 14 regions.

The ability to expand non-agricultural land in the different aggregation schemes is explored further in Figure 5, which shows the portion of potentially arable land that is "non-agricultural" grasslands and forests in each of the 14 states, as well as the average carbon contents of these land use types. When the study region is modeled as a single land use region, $35 \%$ of the potentially arable land is considered to be non-agricultural, consisting of mostly forests $(30 \%)$, with some non-grazed grasslands (5\%). This quantity of forested land is therefore (a) large enough that economic incentives to afforestation can translate to a significant quantity of land, and (b) small enough that there is plenty of agricultural land available for conversion to non-agricultural purposes, in a policy environment that values terrestrial carbon storage. 


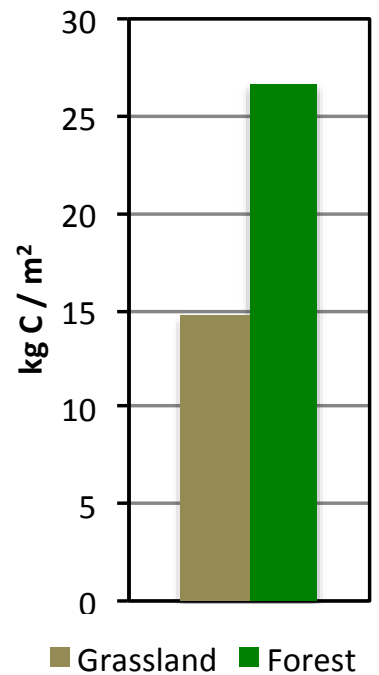

Figure 5. Base-year shares of non-agricultural land by state and land use type (left panel), and average equilibrium carbon density of non-agricultural land use types in the entire study region in the base year (right panel). Dashes in the left panel indicate the range of non-agricultural land shares observed in the crop management zones (CMZs) within each state.

However, when the study region is modeled as 14 states, the two conditions described above do not apply in many of the individual states. As shown, the fractions of nonagricultural land vary strongly by state, from $0 \%$ in Nebraska to $76 \%$ in West Virginia. Moreover, in the states with low shares of non-agricultural lands, these lands tend to be grasslands, which have lower average carbon densities than forests (Figure 5). These low carbon densities reduce any carbon-sequestration-driven economic incentives to take lands out of agricultural production in these states. Conversely, in the states where nonagricultural lands tend to be forested, most of the land is already not in agricultural production, minimizing the extent to which future afforestation may contribute to $\mathrm{CO}_{2}$ sequestration.

The left panel of Figure 5 also illustrates the variability in non-agricultural land shares observed in the CMZs within each of the 14 states. This indicates that the states with either high or low non-agricultural land shares tend to have little differences in these shares between their CMZs. However the states with moderate shares of non-agricultural 
lands do demonstrate variation, similar to what was observed in going from the single study region to the 14 states, though of lesser magnitude. Where the 14 states spanned $76 \%$, the greatest degree of variation across CMZs within states is $40 \%$, in Minnesota.

Taken together, the geographical heterogeneity in both the historical management practices and the physiography of the study region causes notably different model responses when the region is modeled as a single unit, as compared with state-level resolution. In all cases assessed, we observe a greater extent of land use change in response to economic incentives if only one single region is modeled. However, at the scale of the entire study region, the differences between the 14- and 37-sub-region are not as pronounced, or as consistent.

We wish to stress here that for GCAM's land use modeling, finer spatial resolution does not necessarily make the results better or more consistent with historical observations. Note that this differs from Dietrich et al. (2013), where model output at the finest resolution was considered to be of the highest quality, and was used as the basis from which to assess the performance of various aggregation schemes. Because GCAM's longterm land use shares for any modeled region are anchored in the observed calibration shares, the use of small land use regions may limit future land use change, simply because some potential uses are very low or not present in the base year. In GCAM, with the exception of exogenously specified "new" uses of land such as ligno-cellulosic bioenergy production, any land uses that are not present (or have very low land allocation) in the base year in a given land use region are effectively excluded in all future periods as well. In this modeling paradigm, therefore, the size of the land use regions should be large enough to reflect the real-world heterogeneity of potential uses of land in each region, but physiographically homogeneous enough to prohibit unrealistic transitions between land uses.

\section{State-level results}

Where the previous section focused on the pilot region as a whole, this section addresses model outcomes in the individual states. Due to the large number of response variables to assess, which includes 14 states, 7 land cover classes, 2 levels of regional aggregation (the single-region aggregation level does not apply here), 3 levels of emissions mitigation 
policy, and 3 time periods, at this point we apply the multivariate analysis methods described above. The full dataset from the NMDS ordination is shown in Table A1; Figure 6 shows the NMDS ordination of the 14 states' base-year land shares, from which three distinct clusters of states are described here:

1) Nebraska, and North and South Dakota (upper left): Great Plains states with high shares of land (39\% to $66 \%)$ allocated to producing dedicated fodder crops and grass.

2) Illinois, Indiana, and Iowa (lower center): the majority of land (48\% to $61 \%)$ is allocated to producing corn and oil crops (mostly soybeans).

3) Michigan, New York, Pennsylvania, West Virginia, and Wisconsin (upper right): most land (64\% to $79 \%)$ is not in agricultural production.

The remaining states—Minnesota, Ohio, and Kentucky—do not easily fit these three categories, in that between $40 \%$ and $50 \%$ of their land is non-agricultural, but Kentucky also has a fair amount allocated to fodder crops and grass (32\%), and Ohio and Minnesota allocate land to corn and oil crop production (33\% and 21\%, respectively). 


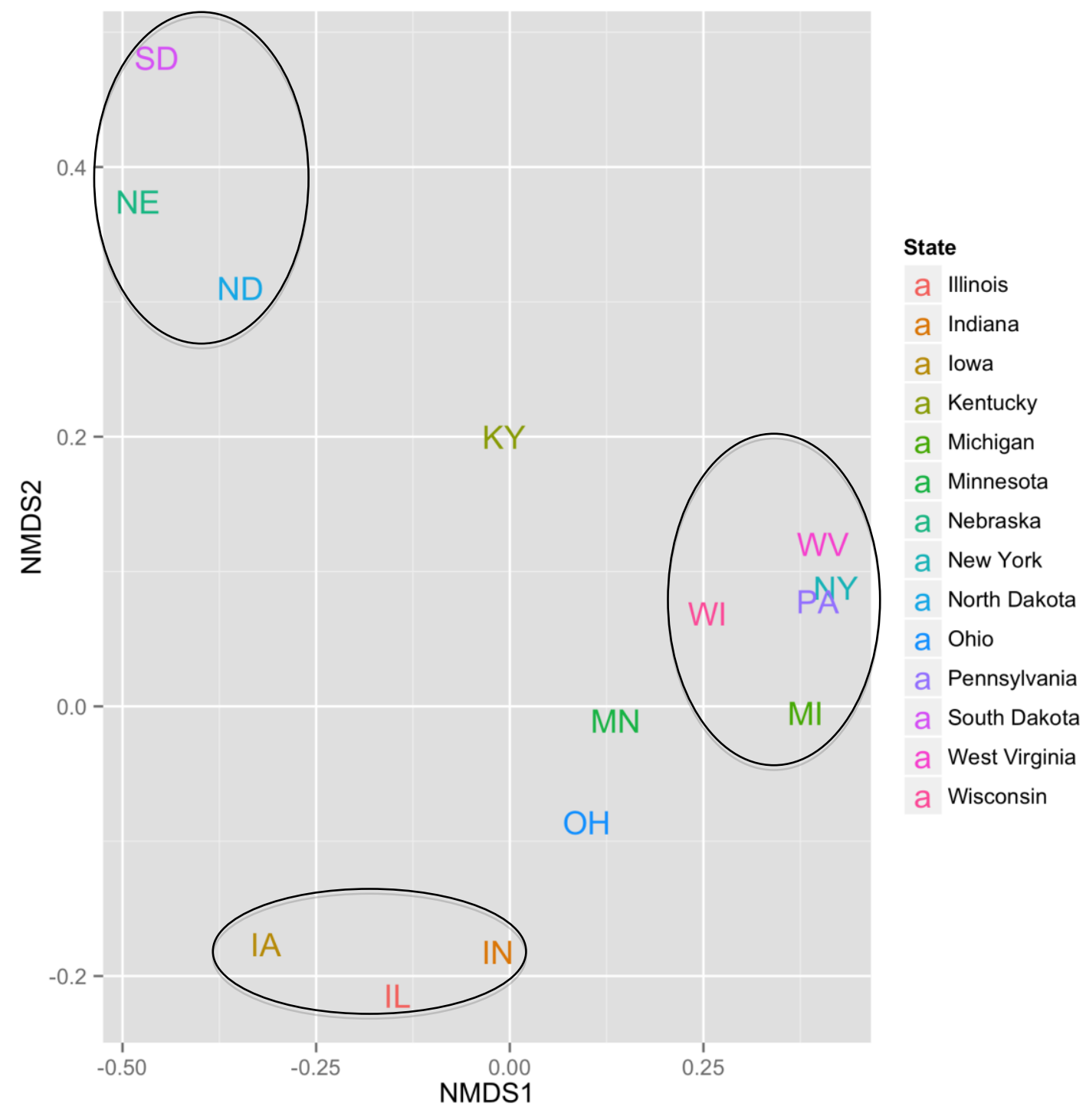

Figure 6. Non-metric multi-dimensional scaling ordination of the land cover differences between the 14 states in the base year (2005).

Figure 7 indicates the evolution of the states from the base year to 2050 and 2095 with no emissions mitigation policy; in this scenario, the primary drivers of the future land use changes are increases in agricultural crop yields and commodity demands both in this region and at a global level, which together determine the changes in commodity prices, and in turn the profitability of each land use option. As noted in Figure 3, the largest shift in land use in these scenarios is from non-agricultural land to bioenergy production. 


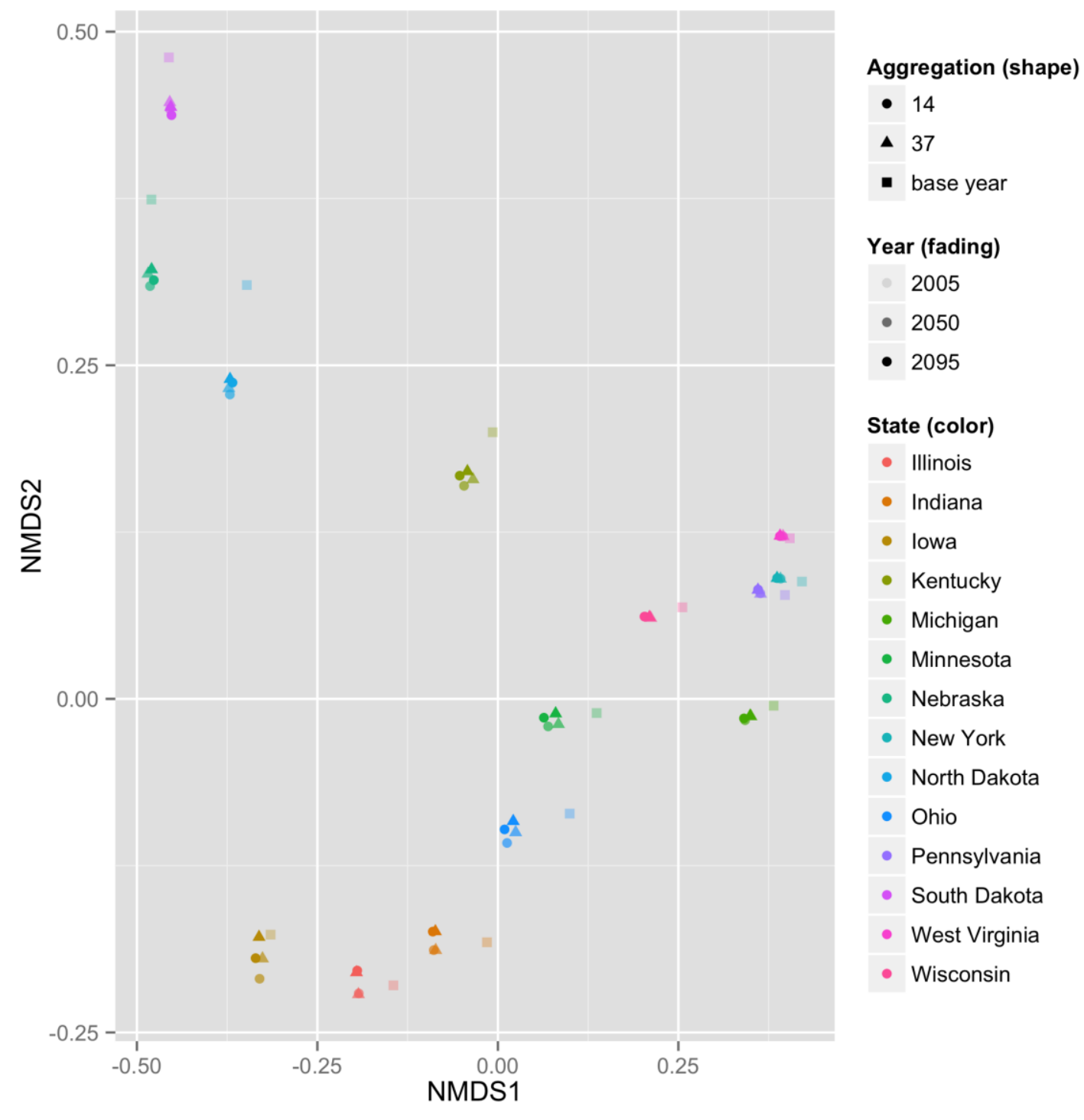

Figure 7. Non-metric multi-dimensional scaling ordination of land cover in 14 states; the coordinate positions are determined by land cover shares. Variables shown include the different states (colors), three different years (fading), and two different levels of regional aggregation (shape; 14 states, and 37 states/CMZs), in scenarios with no emissions mitigation policies.

In Figure 7, the states' positions in 2050 and 2095 tend to move down and left in the NMDS ordination, but their positions relative to one another over time remain similar. With the exception of Pennsylvania and New York, whose base-year positions in the 
graph are quite close, all states' positions in 2050 and 2095 are closer to their own positions in the base year than to any other states in any time periods.

Of particular interest for the present analysis, the future output with 14 states appears quite similar to the output with 37 states and CMZs, though in nearly all cases the 14state output (circles in Figure 7) is farther from the base-year starting point than the 37 states and CMZs. In other words, running with 14 states appears to systematically permit slightly more land use change than the 37 subregions, consistent with the observation from Figure 3 and Figure 4 that the land use types are simply more easily changed when running with larger levels of spatial aggregation. In order to quantify the magnitude of the differences, Table 3 shows land cover shares by land use type in Kentucky, a state that clearly has the 14-state ordination points farther from the base-year starting point than the 37-state-and-CMZ ordination points. Table 3 indicates that the magnitude of the differences between the 14- and 37- region aggregation are small and not uniform; the effects of the different aggregation here are particularly small in comparison with the uncertainties of future land use in general.

Table 3. Land shares by land use type from 2005 to 2050 in Kentucky with 37 states and CMZs as compared with 14 states, with no mitigation policy.

\begin{tabular}{lccc} 
& Base-year & $37: 2050$ & $14: 2050$ \\
\hline Bioenergy & $0.0 \%$ & $5.4 \%$ & $5.3 \%$ \\
Corn & $5.2 \%$ & $7.1 \%$ & $7.5 \%$ \\
Livestock & $32.0 \%$ & $31.3 \%$ & $31.4 \%$ \\
Non-agricultural & $39.7 \%$ & $37.4 \%$ & $36.5 \%$ \\
Oil crops & $5.6 \%$ & $5.4 \%$ & $5.8 \%$ \\
Other crops & $16.0 \%$ & $11.9 \%$ & $12.0 \%$ \\
Wheat & $1.4 \%$ & $1.4 \%$ & $1.5 \%$ \\
\hline
\end{tabular}

The policy variable is the primary focus of Figure 8, which compares the responses of the 14 states from 2005 to 2050 in a business-as-usual policy environment to the responses under emissions mitigation policies consistent with stabilization of global radiative forcing at $4.5 \mathrm{~W} / \mathrm{m}^{2}$ and $3.7 \mathrm{~W} / \mathrm{m}^{2}$. The policies implemented in the model include terrestrial carbon sequestration as a means of emissions mitigation, and the scenarios are 
characterized by a greater degree of land change from 2005 to 2050 than was shown for reference scenarios in Figure 7. Thus, in the NMDS ordination, many states move far from their base-year positions (Figure 8). Still, there is typically little difference in position between points that only differ in whether 14 or 37 sub-regions are used; note that in Iowa and Ohio, statistical discrepancies in the base-year datasets actually caused slightly different starting land allocations, ${ }^{1}$ and these calibration differences persist in future periods. Among the remaining states, Nebraska is the only one that appears to have somewhat divergent behavior when sub-divided into four CMZs, due to relatively low simulated bioenergy yields (and therefore land allocation) in CMZ 05.

\footnotetext{
${ }^{1}$ In these states, the disaggregation of cropland from the state to the CMZ caused the USDA-based sum of harvested area of all crops to exceed the HYDE-based estimate of total cropland in one $\mathrm{CMZ}$, and to be lower in another. GCAM represents such a case as one $\mathrm{CMZ}$ with cropping intensity greater than one harvest per year, and the other $\mathrm{CMZ}$ with cropland that is not assigned to a specific crop. The reason for this discrepancy is that the HYDE gridded cropland inventory was built from state-level USDA data, whereas our disaggregation to CMZ is based on county-level USDA data.
} 


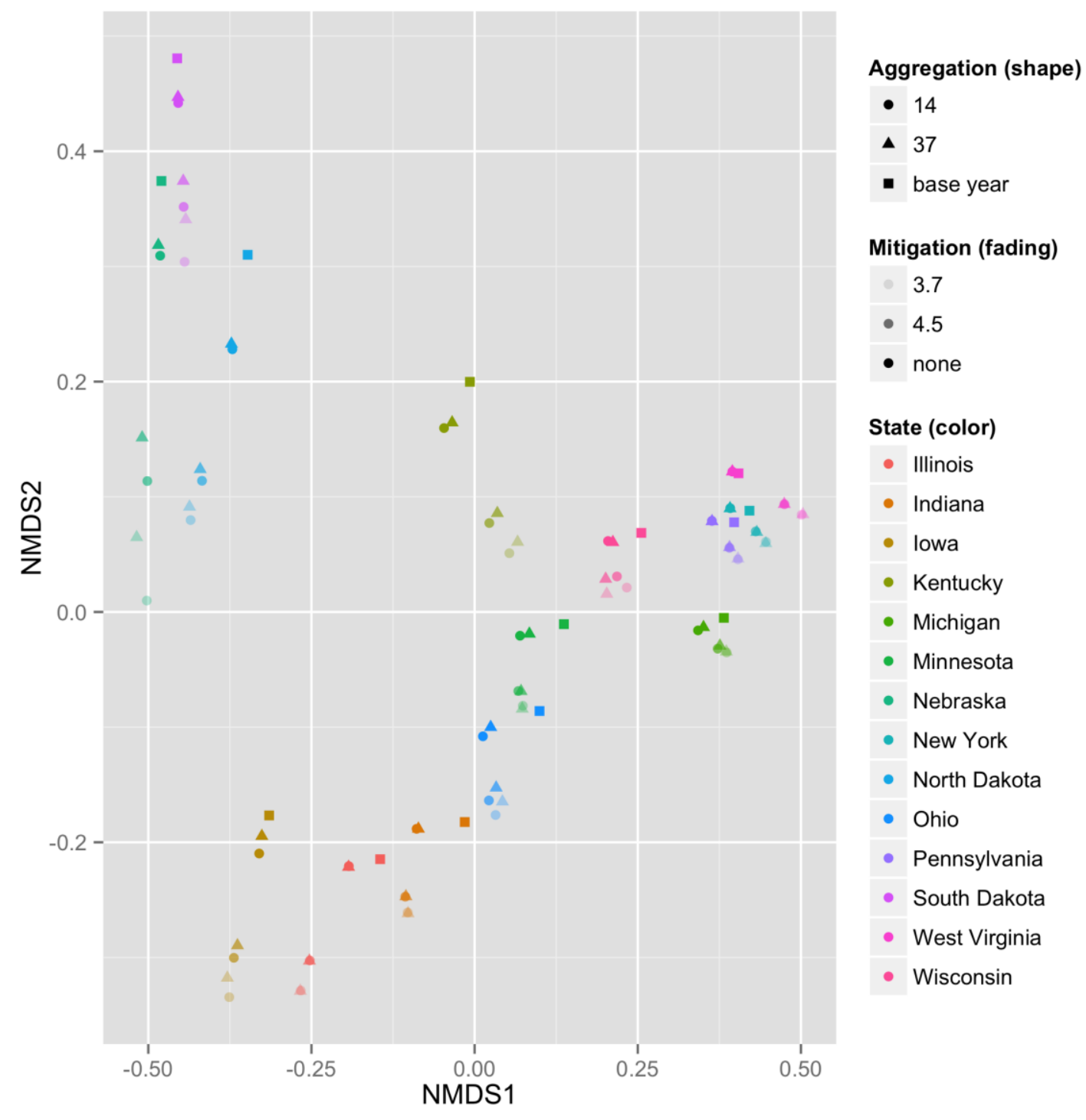

Figure 8. Non-metric multi-dimensional scaling ordination of land cover in 14 states; the coordinate positions are determined by land cover shares. The color indicates the states, the shape indicates the level of regional aggregation (14 states or 37 states and CMZs), and the fading indicates the emissions mitigation level (no mitigation, $4.5 \mathrm{~W} / \mathrm{m}^{2}$, and $3.7 \mathrm{~W} / \mathrm{m}^{2}$ ). Squares indicate 2005 values, and all other points are for 2050.

In comparing any state's future land use in any scenario to its base-year starting point, both the direction and the magnitude of the change on each NMDS axis contain information about the changes in land cover shares. However, the NMDS ordination 
values alone can not be easily translated back to the underlying land cover shares; instead, the meaning of the values in the ordination must be inferred from analysis of the underlying land cover data. In this context, this tool is most useful for multi-region analysis when used to supplement rather than replace analysis of the underlying data on land cover shares. Between the land cover shares shown in Figure 2 and Figure 3 and the ordinations shown in Figure 6, Figure 7, and Figure 8, we infer that down and left generally indicates more land allocated to corn, oil crops, and bioenergy crops; up and left indicates fodder crops; and right indicates non-agricultural land.

Consistent with this observation, the change from the base year shown for each point in Figure 8 generally indicates one of two broad changes brought about by emissions mitigation policy, as compared with the corresponding business-as-usual scenario: states that are mostly agricultural tend to move down and left, whereas states that are mostly non-agricultural move even further right. Within the agricultural states, these changes imply a shift away from fodder crops and grass, and towards corn, oil crops, and bioenergy crops. Figure 9 shows these dynamics in terms of land shares in Nebraska and Illinois, which allocate more land to corn production and less land to livestock and nonagricultural land, in going from 2005 to 2050 business-as-usual and further still in the policy scenario in 2050 . 


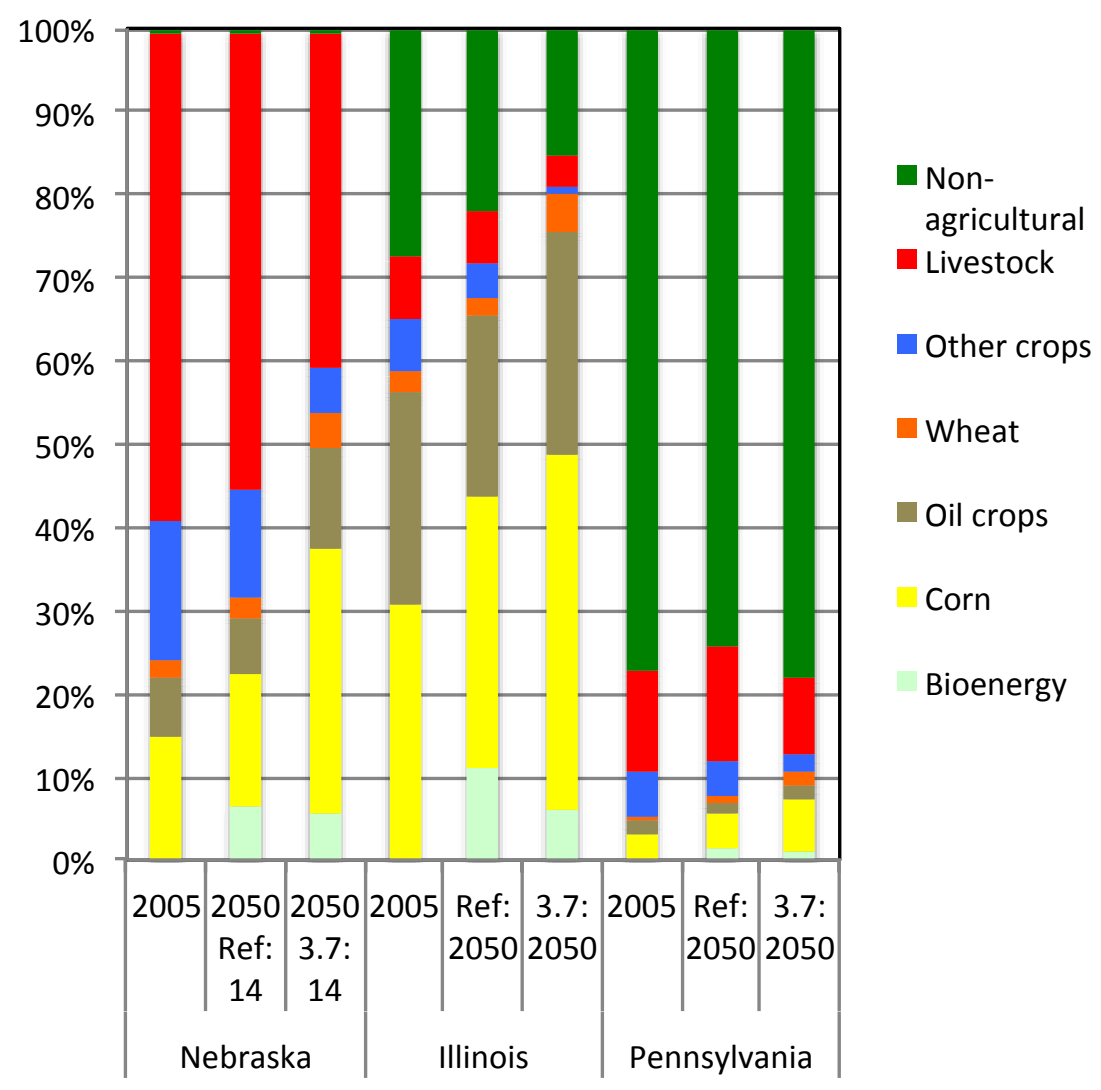

Figure 9. Land cover shares for three selected representative states in 2005 and in 2050, with no mitigation policy and with a $3.7 \mathrm{~W} / \mathrm{m} 2$ policy. The aggregation level used is 14 states.

However, for the mostly non-agricultural states, the behavior in the mitigation scenarios marks a departure from the business-as-usual trends; this reversal is indicated in Figure 8, as the no-policy points are to the left of the base-year points, whereas the policy points are to the right. This is shown in terms of land cover shares in Figure 9 for Pennslyvania, which increases the land allocated to livestock and crops in the reference scenario, but in the mitigation scenario expands non-agricultural lands to an even greater extent than the base year, where these lands accounted for $77 \%$ of the land cover in the state.

To summarize the state-level responses, in states such as Iowa and Nebraska, where nonagricultural lands are relatively low-carbon grasslands and corn yields are high, the emissions mitigation policy with land carbon pricing tends to further increase the use of land for corn production. Conversely, in the states where crop yields are low and non- 
agricultural lands tend to be high-carbon forests, the policy tends to further increase the land allocated to forest. These responses are seen to a similar extent regardless of whether states are further sub-divided into CMZs.

\section{Limitations}

This section briefly outlines some limitations to the present analysis. First, land use change responses to the variables assessed are limited to the mechanisms considered by the model, and the assumptions to the scenarios in this study. While the scenarios explore the effects of emissions mitigation policies, we have not assessed climate change impacts, nor alternative scenarios of crop yields, water scarcity, nutrient availability, costs of capital, or other related factors that may influence future agricultural productivity in the study region or globally. Similarly, the scenario set does not consider alternative socioeconomic development pathways that would be relevant for agricultural commodity demand levels in the USA or globally. Second, in our minimum level of aggregation, the land use regions are still substantially larger than the grid cells used by several integrated assessment models as fundamental land use regions. However, this is intentional, as in contrast to optimization-based representations used in models with grid cell land use regions, GCAM's land sharing is more anchored to base-year shares, and would not perform well at spatial scales with homogeneous land allocation in the base year. Finally, where much of the modeled response to terrestrial carbon pricing was determined by the capacity of lands taken out of agriculture to sequester carbon, our land carbon densities were estimated from base-year vegetation patterns and assumed carbon densities of various ecosystem types, not derived from physiology- or ecosystem-based vegetation modeling.

\section{Conclusions}

In summary, we find that the levels of spatial aggregation are important not for the direction of the response to future drivers of land use change in the U.S., but rather for the degree of change between the land use types, and the magnitude of the land use change in response to a given set of drivers. For this study region, a physiographically diverse area that is responsible for about 80 percent of U.S. corn and soy production, but also has vast tracts of non-agricultural forests, modeling the region with no further sub- 
regionalization allows a greater extent of future land use change than sub-regionalizing to 14 states or to 37 states and CMZs. The reason appears to be that the single-region approach fails to account for the physiographic heterogeneity between the different parts of the region. In this region, the more agricultural western states' agricultural lands would most likely transition to grasslands if taken out of crop production, whereas the forested lands of the eastern states would have comparatively low yields if put into agricultural production. This specialization tends to make land use shares more anchored in their present-day allocations when smaller spatial regions are modeled.

However, we find little difference from increasing the number of sub-regions from 14 to 37 , either at the scale of the whole study region or at the state level. In this context, modeling at the state and CMZ level may still be useful for analysis of dynamics within individual states, but for the state- or region-level assessment, we find little evidence supporting the necessity to capture the within-state variation at the CMZ level. In fact, in several states, including this layer of detail enhances discrepancies between the gridded and census-based estimates of base-year land allocations, modifying the base-year dataset. Still, we also do not see any evidence that the 37 sub-region approach is so highly resolved that future land use change becomes limited in scope; other than the additional processing time and resources, there do not appear to be costs to adopting this approach.

Finally, this study demonstrates that for analysis of agro-economic model output on land shares, multi-variate statistical techniques can assist with the interpretation of model output, particularly when comparing output across many regions, land cover types, and scenarios. The analysis methods here could be applied at larger scales, for instance to geopolitical regions, or at smaller scales, provided that the number of individual observations does not hinder one's ability to see responses. As global and regional agroeconomic models continue to enhance the resolution of the spatial units at which land use decisions are made, tools such as the ones used in this study will likely prove valuable, if not essential, for analysis and visualization of results. 


\section{Acknowledgements}

This research was supported by the Office of Science of the U.S. Department of Energy through the Integrated Assessment Research Program as part of the Regional Integrated Assessment Modeling (RIAM) project (KP1703030). This research leveraged capabilities that were funded by the Platform for Regional Integrated Modeling and Analysis Initiative (PRIMA), which was conducted under the Laboratory Directed Research and Development Program at Pacific Northwest National Laboratory (PNNL). PNNL is operated for DOE by Battelle Memorial Institute under contract DE-AC05-76RL01830. GPK conducted GCAM simulations and NMDS statistical analysis; XZ provided the high resolution input dataset and interpretation; AMT and GPK conceived of the study; MAW provided interpretation of GCAM results; GPK, AMT and MAW wrote the paper. XZ's contributions were funded by the DOE Great Lakes Bioenergy Research Center (DOE BER Office of Science DE-FC02-07ER64494, DOE BER Office of Science KP1601050, DOE EERE OBP 20469-19145). The views and opinions expressed in this paper are those of the authors alone.

\section{References}

Britz, W., P. H. Verburg, and A. Leip. 2011. Modelling of land cover and agricultural change in Europe: combining the CLUE and CAPRI-Spat approaches. Agriculture, Ecosystems, and Environment 142: 40-50.

Channan, S., K. Collins, and W. R. Emanuel. 2014. Global mosaics of the standard MODIS land cover type data. University of Maryland and the Pacific Northwest National Laboratory, College Park, Maryland, USA. http://glcf.umd.edu/data/lc/index.shtml

Dietrich, J.P., Popp, A., and Lotze-Campenn, H. 2013. Reducing the loss of information and gaining accuracy with clustering methods in a global land-use model. Ecological Modelling 263: 233-243.

European Space Agency, 2014. Land Cover - CCI Product User Guide Version 2. Issue 2.4. http://maps.elie.ucl.ac.be/CCI/viewer/index.php

Fujimori, S., Hasegawa, T., Masui, T., and Takahashi, K. 2014. Land use representation in a global CGE for long-term simulation: CET vs. logit functions. Food Security 6: 685-699.

Glotter, M., Elliot, J., McInerney, D., Best, N., Foster, I., and Moyer, E. 2014. Evaluating the utility of dynamical downscaling in agricultural impacts projections. Proceedings of the National Academy of Sciences of the United States of America. doi: 10.1073/pnas.1314787111. 
Havlík, P., Schneider, A.U., Schmid, E., Böttcher, H., Fritz, S., Skalský, R., Aoki, K., de Cara, S.,

Kindermann, G., Kraxner, F., Leduc, S., McCallum, I., Mosnier, A, Sauer, T. and Obersteiner, M. (2011). Global land-use implications of first and second generation biofuel targets. Energy Policy 39: 5690-5702.

Heistermann, M., C Müller, K Ronneberger. 2006. Land in sight? Achievements, deficits and potentials of continental to global scale land-use modeling. Agriculture, Ecosystems and Environment. 114:141-158. doi:10.1016/j.agee.2005.11.015

Hejazi, M., Edmonds, J., Clarke, L., Kyle, P., Davies, E., Chaturvedi, V., Wise, M., Patel, P., Eom, J., Calvin, K., Moss, R., and Kim, S. 2014. Long-term global water projections using six socioeconomic scenarios in an integrated assessment modeling framework. Technological Forecasting and Social Change 81: 205-226.

Hurtt, G.C., Chini, L.P., et al. 2011. Harmonization of land-use scenarios for the period 1500-2100: 600 years of global gridded annual land-use transitions, wood harvest, and resulting secondary lands. Climatic Change 109: 117-161.

IPCC, 2013: Climate Change 2013: The Physical Science Basis. Contribution of Working Group I to the Fifth Assessment Report of the Intergovernmental Panel on Climate Change [Stocker, T.F., D. Qin, G.-K. Plattner, M. Tignor, S.K. Allen, J. Boschung, A. Nauels, Y. Xia, V. Bex and P.M. Midgley (eds.)]. Cambridge University Press, Cambridge, United Kingdom and New York, NY, USA, 1535 pp.

Johnson, D.M., Mueller, R., 2010. The 2009 cropland data layer. Photogrammetric Engineering and Remote Sensing 76 (11) 1201-1205.

Kriegler et al. (2014): Making or breaking climate targets: The AMPERE study on staged accession scenarios for climate policy, DOI: 10.1016/j.techfore.2013.09.021

Kruskal, J.B. 1964. Multidimensional scaling by optimizing goodness of fit to a nonmetric hypothesis. Psychometrika, 29:1-27.

Klein Goldewijk, K., A. Beusen, M. de Vos, G. van Drecht (2011), The HYDE 3.1 spatially explicit database of human induced land use change over the past 12,000 years. Global Ecol. Biogeogr. 20, 73-86, doi:10.1111/j.1466-8238.2010.00587.x.

Kyle, P., P. Luckow, K. Calvin, W. Emanuel, M. Nathan, and Y. Zhou (2011), GCAM 3.0 Agriculture and Land Use: Data Sources and Methods. Pacific Northwest National Laboratory. PNNL-21025.

Legendre, P., and Legendre, L. 1998. Numerical Ecology. Elsevier, Amsterdam.

Lotze-Campenn, H., Muller, C., Bondeau, A., Rost, S., Popp, A., and Lucht, W. 2008. Global food demand, productivity growth, and the scarcity of land and water resources: a spatially explicit mathematical programming approach. Agricultural Economics 39: 325-338. 
Mas, J.-F., M. Kolb, M. Paegelow, M.T. Camacho Olmedo, and T. Houet. 2014. Inductive pattern-based land use/land cover change models: a comparison of four software packages. Environmental Modelling \& Software 51: 94-111.

Masui, T., K. Matsumoto, Y. Hijioka, T. Kinoshita, T. Nozawa, S. Ishiwatari, E. Kato, P.R. Shukla, Y. Yamagata, and M. Kainuma (2011), An emission pathway for stabilization at $6 \mathrm{Wm}-2$ radiative forcing. Climatic Change 109, 59-76, doi:10.1007/s10584-011-0150-5.

McCune, B., and Grace, J.B. 2002. Analysis of Ecological Communities. MjM Software Design, Gleneden Beach, Oregon.

Monfreda, C., N. Ramankutty, and T. Hertel (2009), Global Agricultural Land Use Data for Climate Change Analysis. In T.W. Hertel, S. Rose, and R.S.J. Tol (eds): Economic Analysis of Land Use in Global Climate Change Policy. Routledge.

Mosnier, A., Havlik, P., Valin, H., Baker, J., Murray, B., Feng, S., Obersteiner, M., McCarl, B.A., Rose, S.K., and Schneider, U.A. 2013. Alternative U.S. biofuel mandates and global GHG emissions: The role of land use change, crop management and yield growth. Energy Policy 57: 602-614.

Murray-Rust, D., C. Brown, J. van Vliet, S.J. Adam, D.T. Robinson, P.H. Verburg, and M. Rounsevell. 2014. Combining agent functional types, capitals and services to model land use dynamics. Environmental Modelling \& Software 59: 187-201

Nelson, G.C., Valin, H., et al. 2014. Climate change effects on agriculture: Economic responses to biophysical shocks. Proceedings of the National Academy of Sciences of the United States of America 111: 3274-3279.

Paltsev, S., J, Reilly, H. Jacoby, R. Eckaus, J. McFarland, M. Sarofim, M. Asadoorian and M. Babiker, 2005. "The MIT Emissions Prediction and Policy Analysis (EPPA) Model: Version 4." MIT Joint Program on the Science and Policy of Global Change, Report 125, Cambridge, Massachusetts, August 2005. Available at http://web.mit.edu/globalchange/www/MITJPSPGC_Rpt125.pdf

Popp, A., S K Rose, K Calvin, et al., 2013. Land-use transition for bioenergy and climate stabilization: model comparison of drivers, impacts and interactions with other land use based mitigation options. Climatic Change. 123: 495-509. DOI 10.1007/s10584-013-0926-x

Portmann, F.T., S. Siebert, and P. Döll (2010), Global monthly irrigated and rainfed crop areas around the year 2000: a new high-resolution data set for agricultural and hydrological modeling. Global Biogeochem. Cy. 24, GB 1011, doi:10.1029/2008GB003435.

Rosegrant, M. W., S. Msangi, C. Ringler, T. B. Sulser, T. Zhu, and S. A. Cline. 2008. International Model for Policy Analysis of Agricultural Commodities and Trade (IMPACT): Model description. Washington, D.C.: International Food Policy Research Institute. Available at http://www.ifpri.org/themes/impact/impactwater.pdf.

Schmitz, C., van Meijl, H., Kyle, P., Nelson, G., et al. 2014. Land-use change trajectories up to 2050: insights from a global agro-economic model comparison. Agricultural Economics 45: 69-84. 
Thomson, A.M., K.V. Calvin, S.J. Smith, G.P. Kyle, A. Volke, P. Patel, S. Delgado-Arias, B. BondLamberty, M.A. Wise, L.E. Clarke, and J.A. Edmonds (2011), RCP 4.5: a pathway for stabilization of radiative forcing by 2100. Climatic Change 109, 77-94, doi:10.1007/s10584-0110151-4.

Thomson, A.M., Kyle, G.P., Zhang, X., Bandaru, V., West, T.O., and Wise, M.A. 2014. The contribution of future agricultural trends in the US Midwest to global climate change mitigation. Global Environmental Change 24: 143-154.

USDA-NASS, 2012. Data and Statistics. United States Department of Agriculture, National Agriculture Statistics Service.

USDA-NRCS. 2014. Crop Management Templates. United States Department of Agriculture, Natural Resources Conservation Service. Available at http://www.nrcs.usda.gov/wps/portal/nrcs/detail/national/technical/tools/rusle2/?cid=stelprdb1247 $\underline{555}$.

Van Vuuren, DP, B Eickout, PL Lucas, MGJ den Elzen. 2006. Long-term multi-gas scenarios to stabilize radiative forcing - exploring costs and benefits within an integrated assessment framework. The Energy Journal. SI. 10.5547/ISSN0195-6574-EJ-VolSI2006-NoSI3-10

Von Lampe, M., Willenbockel, D., Ahammad, H., et al. 2014. Why do global long-term scenarios for agriculture differ? An overview of the AgMIP Global Economic Model Intercomparison. Agricultural Economics 45: 3-20.

Waldhoff ST, J Martinich, M Sarofim, BJ DeAngelo, J McFarland, L Jantarasami, A Crimmins, KC Shouse, and J Li. 2014. "Overview of the Special Issue: A Multi-Model Framework to Achieve Consistent Evaluation of Climate Change Impacts in the United States." Climatic Change. doi:10.1007/s10584-014-1206-0 [In Press]

Wise, M.A., K. Calvin, A. Thomson, L. Clarke, B. Bond-Lamberty, R. Sands, S.J. Smith, A. Janetos, and J. Edmonds (2009), Implications of limiting CO2 concentrations for land use and energy. Science 324(5931), 1183-1186, doi:10.1126/science.1168475.

Wise, MA, KV Calvin, GP Kyle and P Luckow. 2014. Economic and Physical Modeling of Land Use in GCAM 3.0 and an Application to Agricultural Productivity, Land, and Terrestrial Carbon. Climate Change Economics (in press)

You, L., S. Wood, U. Wood-Sichra. 2006. Generating global crop maps: from census to grid. Selected paper, IAAE (International Association of Agricultural Economists) Annual Conference, Gold Coast, Australia.

Zhang, X., R.C. Izaurralde, D.H. Manowitz, R. Sahajpal, T.O. West, A.M. Thomson, M. Xu, K. Zhao, S.D. LeDuc, J.R. Williams. 2014. Regional scale cropland carbon budgets: Evaluating a geospatial 
agricultural modeling system using inventory data. Environmental Modelling \& Software (In press). 